\title{
UNIVERSITYOF
}

FORWARD

THINKING

WESTMINSTER用

WestminsterResearch

http://www.westminster.ac.uk/westminsterresearch

\section{Associations between Belief in Conspiracy Theories and the Maladaptive Personality Traits of the Personality Inventory for DSM-5}

Swami V., Weis L., Ley A., Barron D. and Furnham A.

NOTICE: this is the authors' version of a work that was accepted for publication in Psychiatry Research. Changes resulting from the publishing process, such as peer review, editing, corrections, structural formatting, and other quality control mechanisms may not be reflected in this document. Changes may have been made to this work since it was submitted for publication. A definitive version was subsequently published in Psychiatry Research, 236, 86-90, 0165-1781.

Psychiatry Research is available online at:

https://dx.doi.org/10.1016/j.psychres.2015.12.027

(C) 2016. This manuscript version is made available under the CC-BY-NC-ND 4.0 license http://creativecommons.org/licenses/by-nc-nd/4.0/

The WestminsterResearch online digital archive at the University of Westminster aims to make the research output of the University available to a wider audience. Copyright and Moral Rights remain with the authors and/or copyright owners.

Whilst further distribution of specific materials from within this archive is forbidden, you may freely distribute the URL of WestminsterResearch: ((http://westminsterresearch.wmin.ac.uk/)).

In case of abuse or copyright appearing without permission e-mail repository@westminster.ac.uk 
Running head: CONSPIRACY THEORIES

Associations between Belief in Conspiracy Theories and the Maladaptive Personality Traits of the Personality Inventory for DSM-5

Viren Swami $^{\mathrm{a}-\mathrm{b}^{*}}$, Laura Weis ${ }^{\mathrm{c}}$, Alixe Lay Cui Ling ${ }^{\mathrm{d}}$, David Barron ${ }^{\mathrm{a}}$, \& Adrian Furnham ${ }^{\mathrm{c}}$

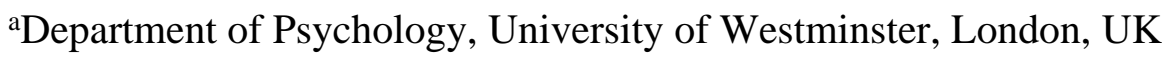

${ }^{b}$ Department of Psychology, HELP University College, Kuala Lumpur, Malaysia

'Department of Clinical, Educational, and Health Psychology, University College London, London, UK

${ }^{\mathrm{d}}$ Department of Psychology, University of Bath, Bath, UK

*Address correspondence to: Dr. Viren Swami, Department of Psychology, Faculty of Science and Technology, University of Westminster, 115 New Cavendish Street, London W1W 6UW, UK. Email: v.swami@westminster.ac.uk; Telephone: +442079115000. 


\begin{abstract}
Conspiracy theories can be treated as both rational narratives of the world as well as outcomes of underlying maladaptive traits. Here, we examined associations between belief in conspiracy theories and individual differences in personality disorders. An Internet-based sample $(N=259)$ completed measures of belief in conspiracy theories and the 25 facets of the Personality Inventory for DSM-5 (PID-5). Preliminary analyses showed no significant differences in belief in conspiracy theories across participant sex, ethnicity, and education. Regression analyses showed that the PID-5 facets of Unusual Beliefs and Experiences and, to a lesser extent, Suspiciousness, significantly predicted belief in conspiracy theories. These findings highlight a role for maladaptive personality traits in understanding belief in conspiracy theories, but require further investigation.

Keywords: Conspiracy theories, Personality disorders, Maladaptive traits, Unusual beliefs, Suspiciousness
\end{abstract}




\section{Introduction}

Conspiracist beliefs usually refer to a set of false narratives in which multiple agents are believed to be working together toward malevolent ends (Swami \& Furnham, 2014). For example, some people believe that, rather than crashing at sea, Amelia Earhart and Fred Noonan intentionally downed their aircraft near Japanese occupied territory so that the U.S. Navy could spy on the Japanese during the subsequent rescue mission (Swami \& Furnham, 2012). Such beliefs are widespread: data from four nationally representative surveys have shown that half of the American public endorse at least one conspiracy theory (Oliver \& Wood, 2014). In addition to being widespread, belief in conspiracy theories also has negative health, socio-political, and environmental consequences (for a review, see Douglas, Sutton, Jolley, \& Wood, 2015). For example, recent studies have suggested that belief in conspiracy theories is associated with decreased trust in government services and institutions (Glick \& Einstein, 2015) and decreased pro-social behaviour and science acceptance (van der Linden, 2015).

Recent work has attempted to conceptualise conspiracy theories as both neutral, rational narratives of the world and the outcome of psychopathology (e.g., Nefes, 2015). In terms of the former, it is postulated that conspiracy theories offer simplistic explanations for individuals attempting to make sense of events that are confusing, difficult to comprehend, or poorly explained by mainstream sources of information (Swami \& Furnham, 2014). The latter view, on the other hand, suggests that there are maladaptive cognitive-perceptual traits that contribute to the formation or maintenance of anomalous beliefs, including conspiracy theories. While acknowledging that the lens of psychopathology offers only a partial account of the popularity of conspiracy theories, this perspective nevertheless suggests that maladaptive cognitive or perceptual traits may make assimilation or maintenance of conspiracist beliefs more likely (van Elk, 2015). 
In support of this perspective, studies have reported positive associations between belief in conspiracy theories and traits including paranoia, magical ideation, and belief in the paranormal (e.g., Brotherton \& Eser, 2014; Lobato, Mendoza, Sims, \& Chin, 2014; Stieger, Gumhalter, Tran, Voracek, \& Swami, 2013; Swami et al., 2011). In explanation, it has been suggested that conspiracy theories and anomalous beliefs share features in common (e.g., both overly rely on intuitive-experiential processing of information and lack rigorous, selfgenerated testing; Swami, Voracek, Stieger, Tran \& Furnham, 2014) and that endorsement of one set of anomalous beliefs (e.g., belief in the paranormal) makes acceptance of other anomalous beliefs (e.g., conspiracy theories) more likely (Ramsay, 2006). From this perspective, intra-individual endorsement of inadequate explanations for events is a key factor shaping the assimilation and maintenance of maladaptive beliefs (Drinkwater, Dagnall, \& Parker, 2012), but this in itself is not necessarily evidence of underlying maladaptive trait influence.

To address this issue, a number of studies have focused more specifically on associations between belief in conspiracy theories and schizotypy, a set of cognitive, perceptual, and affective traits ranging from normal dissociative states to extreme states. These studies have reported significant and positive associations between belief in conspiracy theories and schizotypy (e.g., Darwin, Neaves, \& Holmes, 2011; Swami et al., 2013), and in explanation it has been suggested that traits of suspiciousness seen in high schizotypal individuals may result in them disbelieving official or mainstream sources of information. Additionally, characteristics associated with paranoid ideation may result in distorted perceptions and a misappreciation of intention that result in conspiracist ideation (Darwin et al., 2011; van der Tempel \& Alcock, 2015).

Despite these findings, there are a number of issues requiring clarification. First, where facets of schizotypy have been examined, it appears that traits associated with odd 
beliefs and magical thinking - the traits most closely associated with belief in the paranormal - are predictive of belief in conspiracy theories, whereas other schizotypal facets show weaker or non-significant associations (Barron, Morgan, Towell, Altemeyer, \& Swami, 2014). Second, it has been reported that it is delusional traits, rather than schizotypy per se, that may lead to greater acceptance of conspiracy theories (Dagnall, Drinkwater, Parker, Denovan, \& Parton, 2015). That is, the association between schizotypy and conspiracist ideation reported in earlier studies may reflect an indirect measurement of delusional ideation in measures of schizotypy. Collectively, these studies suggest that it is a tendency toward paranoia or delusional ideation that shapes belief in conspiracy theories (Dagnall et al., 2015), although more in-depth research is necessary to fully understand these associations.

Here, we sought to clarify aspects of this literature by focusing, not on schizotypy, but rather on maladaptive personality traits. To address concerns with the discrete categorical model of personality pathology used since the third edition of the Diagnostic and Statistical Manual of Mental Disorders (DSM; see Widiger \& Trull, 2007), a dimensional trait model of individual differences in personality disorders is included in Section III of the DSM-5 (American Psychiatric Association, 2013). This model proposes 25 trait facets that are classified into five broad trait domains, four that are suggested to be common to both normal and abnormal personality variation (Antagonism, Negative Affectivity, Detachment, and Disinhibition) and a Psychotism domain that subsumes traits of schizotypy and dissociation (Krueger, Derringer, Markon, Watson, \& Skodol, 2012). This trait assessment provides a multi-level description of personality disorders for DSM-5 and provides a key step in building models of personality pathology.

From the point-of-view of studies on conspiracist ideation, this model offers an opportunity to refine existing knowledge of the relationships between belief in conspiracy theories and maladaptive traits. This can be achieved through the model's broader focus on 
maladaptive personality traits and also by providing orienting dimensions for understanding maladaptive beliefs more generally. That is, by using broad dimensions that span normative and pathological functioning, it becomes possible to develop a reliable scaffold to understand the nature of conspiracist ideation. In addition, given evidence that the DSM-5 dimensional trait model are maladaptive variants of general personality structure (e.g., Gore \& Widiger, 2013), a focus on the former may help to explicate mixed and typically weak associations between conspiracist ideation and the Big Five personality domains (Swami, ChamorroPremuzic, \& Furnham, 2010; Swami et al., 2011; Swami \& Furnham, 2012).

In summary, the present study examined relationships between maladaptive personality facets and belief in conspiracy theories. Of the 25 facets proposed in the DSM-5 dimensional trait model (see Table 1), those associated with the Psychotism domain would seem most likely to be associated with belief in conspiracy theories. These facets tap those constructs that have been identified as predictors of conspiracist ideation in previous studies (Barron et al., 2014; Dagnall et al., 2015), but offer broader coverage of maladaptive personality traits. In addition, the facet of Suspiciousness (subsumed within the domain of Negative Affectivity) would appear to be another potential candidate, given commentary about distrust of others in conspiracist ideation (Drinkwater et al., 2011). Although other facets of the DSM-5 dimensional trait model are less likely to show predictive relationships with belief in conspiracy theories, we nevertheless included them in our analyses.

\section{Method}

\subsection{Participants and Procedures}

A brief description of the study, including estimated duration and compensation, was posted on Amazon's Mechanical Turk (MTurk) website in July 2015. MTurk is a crowdsourcing Internet marketplace that allows individuals to complete online tasks for monetary compensation. The present study was advertised to MTurk workers who achieved 
at least a $98 \%$ approval rate and completed at least 1,000 hits. The study was described to potential participants as an investigation of personality and attitudes toward world events. After providing informed consent, participants were directed to the measures described below (as well as a measure of modern health worries not analysed here; Petrie et al., 2001), which were presented in an anonymous form and in random order via the randomisation function with Qualtrics, which hosted the survey. In exchange for completing the survey, participants were paid $\$ 1.00$. Participants with large amounts of missing data $(n=17)$ were excluded from the dataset. All participants received debriefing information at the end of the survey.

The final sample consisted of 130 women and 129 men, who ranged in age from 19 to 74 years $(M=36.36, S D=11.12)$. Due to an administrative oversight, we did not collect information about participants' country of origin. However, the majority of participants identified as White $(54.1 \%)$, with $25.1 \%$ identifying as Asian, $18.9 \%$ as multiracial, and $1.9 \%$ as some other ethnic group. In terms of educational qualifications, $8.1 \%$ had completed secondary schooling, $23.9 \%$ had a post-secondary qualification, $42.5 \%$ had an undergraduate degree, and $25.5 \%$ had a postgraduate degree.

\subsection{Measures}

Maladaptive personality traits. The Personality Inventory for DSM-5 (PID-5; Krueger et al., 2012) is a 220-item self-report inventory that assesses the maladaptive personality traits proposed in Section III of $D S M-5$. The measure taps 25 maladaptive personality traits, organised based on factor analytic evidence into five broad domains. Each trait is measured by 4 to 14 items, with responses made on a 4-point scale ranging from 0 (Very false or often false) to 3 (Very true or often true). Facet scores were computed as the mean of items associated with each facet. PID-5 scores have been shown to have good internal consistency and factorial validity (Wright et al., 2012), as well as good concurrent validity (Hopwood, Thomas, Markon, Wright, \& Krueger, 2012). Cronbach's $\alpha$ in the current 
sample for the PID-5 domain scale scores were good, while facet scores were acceptable-togood (see Table 1).

Belief in conspiracy theories. Participants completed the Belief in Conspiracy Theories Inventory (BCTI; Swami et al., 2010, 2011), a 15-item measure that describes a range of internationally-popular conspiracy theories. Participants rated their belief that each conspiracy was true on a 9-point scale, ranging from 1 (Completely false) to 9 (Completely true). An overall score was computed as the mean of all items, with higher scores reflecting greater belief in conspiracy theories. Scores on this measure have been shown to be onedimensional (Swami et al., 2011) and correlate strongly with scores from a generic measure of conspiracist ideation ( $r=.88$; Brotherton, French, \& Pickering, 2013). In the present study, Cronbach's $\alpha$ for the BCTI was .93.

Demographic form. Participants provided their demographic details, consisting of sex, age, ethnicity, and highest educational qualification.

\section{Results}

\subsection{Preliminary Analyses}

An independent-samples $t$-test showed no significant differences in belief in conspiracy theories between women $(M=4.15, S D=1.91)$ and men $(M=4.23, S D=1.73)$, $t(257)=0.34, p=.732, d=0.04$. Analyses of variance also showed that, in this sample, there were no significant differences in belief in conspiracy theories between ethnic groups, $F(3$, $255)=2.28, p=.080, \eta_{\mathrm{p}}{ }^{2}=.02$, and between educational groups, $F(3,255)=0.87, p=.456$, $\eta_{\mathrm{p}}{ }^{2}=.01$. Younger participants were more likely to believe in conspiracy theories, $r=-.20, p$ $=.001$, but the effect size was small. For these reasons, we treated the sample as a whole for all further analyses.

\subsection{Regression Analyses}


Belief in conspiracy theories was significantly and positively associated with all five PID-5 domains $(r \mathrm{~s}=|.34|-|.49|)$ and all PID-5 facets $(r \mathrm{~s}=|.24|-|.48|$; see Table 1$)$. Entering the 25 PID-5 facets into a multiple linear regression using belief in conspiracy theories as the criterion variable resulted in a significant regression, but multicollinearity was a limiting issue in this analysis (variance inflation factors $[\mathrm{VIFs}]=2.11-12.38$ ) and remained problematic when domain scores were used as predictor variables instead (VIFs $=2.36-6.87$ ). Although multicollinearity is not a direct statistical assumption of multiple regression analyses (Osborne \& Waters, 2002), it can complicate interpretation of results because of its influence on the magnitude of regression weights and inflation of their standard error, which in turn affects the statistical significance tests of these coefficients (Nimon, Henson, \& Gates, 2010). In short, the presence of multicollinear data makes interpretation of standardised and unstandardised regression coefficients problematic.

To minimise the problems associated with multicollinearity, we followed goodpractice procedures to reduce the number of variables included in the analysis (Dohoo, Ducrot, Fourichon, Donald, \& Hurnik, 1997). The most straightforward way to accomplish this was to screen all PID-5 facets using unconditional statistics and to then select a subset of variables for inclusion in the final analysis. Based on this method, we selected the five PID-5 facets that were most strongly correlated with belief in conspiracy theories (bold coefficients in Table 1): Unusual Beliefs and Experiences, Perceptual Dysregulation, Eccentricity, Suspiciousness, and Callousness. Inter-facet correlations between these five factors were all < |.66| and, as such, were within acceptable parametres for inclusion (Dohoo et al., 1997). These facets were then entered into a multiple linear regression with belief in conspiracy theories as the criterion. This regression was significant, $F(5,253)=18.50, p<.001$, Adj. $R^{2}$ $=.25$, and inspection of the VIFs suggested that multicollinearity was less of a constraining 
issue (VIFs $=2.02-3.35)$. Of the PID-5 facets entered into the model, the only significant predictors were Suspiciousness and Unusual Beliefs and Experiences (see Table 2).

To check that this result was not spurious, we also conducted a stepwise regression with all 25 facets as predictors and belief in conspiracy theories as the criterion variable. Although stepwise regressions typically yield biased $R^{2}$ values and confidence intervals for effects and predicted values that are falsely low (Derksen \& Keselman, 1992), it can be used to confirm the results of linear regressions, especially when dealing with multicollinearity (Kuhn \& Johnson, 2013). The final prediction model contained 2 of the 25 predictors (Unusual Beliefs and Experiences and Suspiciousness) and was reached in two steps, with the remaining 23 facets excluded. This model was statistically significant, $F(2,256)=45.27, p<$ .001 , Adj. $R^{2}=.26$. Belief in conspiracy theories was primarily predicted by Unusual Beliefs and Experiences $\left(\mathrm{B}=.45, S E=.09, B=.34, t=4.73, p<.001, \mathrm{Adj} . R^{2}=.23\right)$, and to a lesser extent by Suspiciousness ( $\mathrm{B}=.36, S E=.12, \beta=.22, t=3.12, p=.002$, Adj. $\Delta R^{2}=.03$ ). VIFs for the analysis were within acceptable parameters (1.76).

\section{Discussion}

In this study, we sought to move the study of conspiracy theories forward by examining associations between belief in conspiracy theories and maladaptive personality traits. Our results showed that belief in conspiracy theories was most strongly associated with the Unusual Beliefs and Experiences facet of the PID-5. In broad outline, this finding is consistent with previous work showing that facets of schizotypy closely associated with odd beliefs and magical thinking are most strongly predictive of belief in conspiracy theories (Barron et al., 2014). While it is clear that there is some shared space occupied by facets of the PID-5 and measures of schizotypy (Ashton, Lee, de Vries, Hendrickse, \& Born, 2012), we believe our findings point to a broader picture of maladaptive personality traits that influence anomalous beliefs, including belief in conspiracy theories. 
One way of interpreting these findings is to suggest that conspiracy theories form (or should be considered as) a subset of anomalous beliefs, akin to paranormal beliefs of magical ideation. Clearly, some conspiracy theories fit this categorisation: to return to the example we provided earlier, believing that Amelia Earhart and Fred Noonan unwittingly made contact with aliens and were abducted during their final flight is delusional (Swami \& Furnham, 2012), given the lack of evidence for the specific claim or for the existing aliens. This being the case, individuals who experience maladaptive cognitive-perceptual processing may be more likely to accept a range of beliefs that are anomalous. This explanation would also help to reports of significant associations between conspiracist ideation and paranormal beliefs (e.g., Brotherton \& Eser, 2014; Lobato et al., 2014; Stieger et al., 2013; Swami et al., 2011). Our suggestion here is that acceptance of both sets of beliefs, as well as other related suppositions, are underscored by the same underlying maladaptive personality facet.

Having said that, it is also clear that not all conspiracy theories are delusional: believing that Earhart and Noonan intentionally downed their aircraft so that the U.S. Navy could spy on the Japanese may be implausible, but it is not entirely impossible (Swami \& Furnham, 2012). Indeed, a common feature of many conspiracy theories is that they present alternative explanations of events that are possible, even if improbable. Defining all conspiracy theories as anomalous beliefs may, therefore, have little utility. Instead, it is possible that the traits tapped by Unusual Beliefs and Experiences - such as an over-reliance on intuitive-experiential processing of information - are conducive to the acceptance of theories and ideas that lack evidence (Swami et al., 2014). That is, an underlying maladaptive personality disposition is conducive to the development of a worldview or worldviews that are more accepting of conspiracy theories (Dagnall et al., 2015).

This finding also sheds light on the positive relationship between the Big Five facet of Openness to Experience and belief in conspiracy theories that has been reported in several 
studies (Swami et al., 2010, 2011), but not others (Swami \& Furnham, 2012). Proponents of the Five-Factor Model of personality have argued that Openness is important when considering personality pathology (Piedmont, Sherman, Dy-Liacco, \& Williams, 2009). Moreover, Openness appears to be associated with the PID-5 domain of Psychoticism, sometimes in opposing directions (Chmielewski, Babgy, Markon, Ring, \& Ryder, 2014). Taking these findings together, it is possible that reports of associations between Openness and belief in conspiracy theories are artefactual. In effect, this association emerges because of shared conceptual space between Openness and Psychoticism as measured by the PID-5. A future study on belief in conspiracy theories that concurrently measures maladaptive personality traits along with facets of Openness to Experience would help to resolve this issue.

The relationship between suspiciousness and belief in conspiracy theories will likewise require further investigation. Here, we found that the facet of Suspiciousness emerged as a significant predictor of belief in conspiracy theories, although it explained only a small proportion of shared variance. In previous work, however, Barron et al. (2014) reported that a schizotypy-based measure of Paranoid Ideation/Suspiciousness did not predict belief in conspiracy theories once the effects of odd beliefs had been accounted for. It would seem, therefore, that suspiciousness is only weakly associated with belief in conspiracy theories. Dagnall et al. (2015) explain that suspiciousness may lead individuals to focus on self-generated or self-affirmed views, but that it is insufficient to produce conspiratorial thinking on its own.

A number of limitations of the present study should be considered. First, because we did not collect information about participant country of origin, it is difficult to know how homogeneous our sample truly is. While we were able to rule out between-group differences in key demographics (ethnicity and education), we were not able to rule out cross-national 
differences. This is important because the function of conspiracy theories may differ across cultural groups (Swami, 2012) and because existing data suggests there may be significant, albeit small, differences across national groups (Bruder, Haffke, Neave, Nouripanah, \& Imhoff, 2013). In a similar vein, while MTurk samples are more demographically-diverse than standard Internet samples and the site is recognised as a source of high-quality data for social science research (Buhrmester, Kwang, \& Gosling, 2011). MTurk participants are also known to be less extraverted and have lower self-esteem than traditional samples (Goodman, Cryder, \& Cheema, 2013). These issues limit the generalisability of our findings, but could be addressed in future work with more precise recruitment methods to ensure representativeness.

These limitations aside, our work sheds light on current theorising about belief in conspiracy theories. It is apparent that maladaptive personality traits play a role in shaping belief in conspiracy theories and may also help to unify the findings of earlier studies. Our argument is that there are underlying traits that are associated with conspiracist ideation and that are being tapped by scholars focused on measures of schizotypy and general personality structure. Of course, it would be wrong to suggest that such belief in conspiracy theories is driven solely by maladaptive personality traits, particularly given the small amount of variance accounted for in our study. Nevertheless, by focusing on these traits, scholars will be able to arrive at a fuller conceptual account of belief in conspiracy theories, which rightly views such beliefs as both rational narratives and shaped by underlying maladaptive traits. 


\section{References}

American Psychiatric Association (2013). Diagnostic and statistical manual of mental disorders ( $5^{\text {th }}$ ed.). Washington, DC: Author.

Ashton, M. C., Lee, K., de Vries, R. E., Hendrickse, J., \& Born, M. P. (2012). The maladaptive personality traits of the Personality Inventory for DSM-5 (PID-5) in relation to the HEXACO personality factors and schizotypy/dissociation. Journal of Personality Disorders, 26, 641-659. doi: 10.1521/pedi.2012.26.5.641

Barron, D., Morgan, K., Towell, T., Altemeyer, B., \& Swami, V. (2014). Associations between schizotypy and belief in conspiracist ideation. Personality and Individual Differences, 70, 156-159. doi: 10.1016/j.paid.2014.06.040

Brotherton, R., \& Eser, S. (2015). Bored to fears: Boredom proneness, paranoia, and conspiracy theories. Personality and Individual Differences, 80, 1-5. doi: 10.1016/j.paid.2015.02.011

Brotherton, R., French, C. C., \& Pickering, A. D. (2013). Measuring belief in conspiracy theories: The Generic Conspiracist Beliefs Scale. Frontiers in Psychology, 4, 279. doi: 10.3389/fpsyg.2013.00279

Bruder, M., Haffke, P., Neave, N., Nouripanah, \& Imhoff, T. (2013). Measuring individual differences in generic beliefs in conspiracy theories across cultures: Conspiracy Mentality Questionnaire. Frontiers in Psychology, 4, 225. doi: 10.3389/fpsyg.2013.00225.

Buhrmester, M., Kwang, T., \& Gosling, S. D. (2013). Amazon's Mechanical Turk: A new source of inexpensive, yet high-quality, data? Perspectives on Psychological Science, 6, 3-5. doi: $10.1177 / 1745691610393980$

Chmielewski, M., Bagby, R. M., Markon, K., Ring, A. J., \& Ryder, A. G. (2014). Openness to Experience, Intellect, schizotypal personality disorder, and Psychoticism: Resolving 
the controversy. Journal of Personality Disorders, 28, 483-499. doi:

10.1521/pedi_2014_28_128

Dagnall, N., Drinkwater, K., Parker, A., Denovan, A., \& Parton, M. (2015). Conspiracy theory and cognitive style: A worldview. Frontiers in Psychology, 6, 206. doi: 10.3389/fpsyg.2015.00206

Darwin, H., Neave, N., \& Holmes, J. (2011). Belief in conspiracy theories: The role of paranormal belief, paranoid ideation and schizotypy. Personality and Individual Differences, 50, 1289-1293. doi: 10.1016/j.paid.2011.02.027

Derksen, S., \& Keselman, H. J. (1992). Backward, forward, and stepwise automated subset selection algorithms: Frequency of obtaining authentic and noise variables. British Journal of Mathematical and Statistical Psychology, 45, 265-282. doi: 10.1111/j.20448317.1992.tb00992.x

Dohoo, I. R., Ducrot, C., Fourichon, C., Donald, A., \& Hurnik, S. (1997). An overview of techniques for dealing with large numbers of independent variables in epidemiologic studies. Preventive Veterinary Medicine, 29, 221-239.

Douglas, K., Sutton, R., Jolley, D., \& Wood, M. (2015). In M. Bilewicz, A. Chichoka, \& W. Sokal (Eds.), The psychology of conspiracy theories. London: Taylor and Francis, in press.

Drinkwater, K., Dagnall, N., \& Parker, A. (2012). Reality testing, conspiracy theories, and paranormal beliefs. The Journal of Parapsychology, 76, 57-77.

Einstein, K. L., \& Glick, D. M. (2015). Do I think BLS data are BS? The consequences of conspiracy theories. Political Behavior, 37, 679-701. doi: 10.1007/s11109-014-9287-z

Goodman, J. K., Cryder, C. E., \& Cheema, A. (2013). Data collection in a flat world: The strengths and weaknesses of Mechanical Turk samples. Journal of Behavioral Decision Making, 26, 213-224. doi: 10.1002/bdm.1753 
Gore, W. L., \& Widiger, T. A. (2013). The DSM-5 dimensional trait model and five-factor models of general personality. Journal of Abnormal Psychology, 122, 816-821. doi: $10.1037 / \mathrm{a} 0032822$

Hopwood, C. J., Thomas, K. M., Markon, K. E., Wright, A. G. C., \& Krueger, R. F. (2012). DSM-5 personality traits and DSM-IV personality disorders. Journal of Abnormal Personality, 121, 424-432. doi: 10.1037/a0026656

Lobato, E., Mendoza, J., Sims, V., \& Chin, M. (2014). Examining the relationship between conspiracy theories, paranormal beliefs, and pseudoscience acceptance among a university population. Applied Cognitive Psychology, 28, 617-625. doi: 10.1002/acp.3042

Nefes, T. S. (2015). Scrutinizing impacts of conspiracy theories on readers' political views: A rational choice perspective on anti-Semitic rhetoric in Turkey. British Journal of Sociology, in press. doi: 10.1111/1468-4446.12137

Nimon, K., Henson, R., \& Gates, M. (2010). Revisiting interpretation of canonical correlation analysis: A tutorial and demonstration of canonical commonality analysis. Multivariate Behavioral Research, 45, 702-724. doi: 10.1080/00273171.2010.498293

Krueger, R. D., Derringer, J., Markon, K. E., Watson, D., \& Skodol, A. E. (2012). Initial construction of a maladaptive personality trait model and inventory for DSM-5. Psychological Medicine, 42, 1879-1890. doi: 10.1017/S0033291711002674

Kuhn, M., \& Johnson, K. (2013). Applied predictive modelling (13 ${ }^{\text {th }}$ ed.). New York, NY: Springer.

Oliver, J. E., \& Wood, T. J. (2014a). Conspiracy theories and the paranoid style(s) of mass opinion. American Journal of Political Science, 58, 952-966. doi: 10.1111/ajps.12084 Petrie, K., Silvertsen, B., Hysing, M., Broadbent, E., Moss-Morris, R., Eriksen, H., \& Ursin, H. (2001). Thoroughly modern worries: The relationship of worries about modernity to 
reported systems, health, and medical care utilization. Journal of Psychosomatic Research, 51, 395-401. doi: 10.1016/S0022-3999(01)00219-7

Ramsay, R. (2006). Conspiracy theories. Harpenden, UK: Pocket Essentials.

Stieger, S., Gumhalter, N., Tran, U. S., Voracek, M., \& Swami, V. (2013). Girl in the cellar: A repeated cross-sectional investigation of belief in conspiracy theories about the kidnapping of Natascha Kampusch. Frontiers in Psychology, 4, 297. doi: 10.3389/fpsyg.2013.00297

Swami, V. (2012). Social psychological origins of conspiracy theories: The case of the Jewish conspiracy theory in Malaysia. Frontiers in Psychology, 3, 280. doi: 10.3389/fpsyg.2012.00280

Swami, V., Chamorro-Premuzic, T., \& Furnham, A. (2010). Unanswered questions: A preliminary investigation of personality and individual difference predictors of 9/11 conspiracist beliefs. Applied Cognitive Psychology, 24, 749-761. Doi: 10.1002/acp.1583

Swami, V., Coles, R., Stieger, S., Pietschnig, J., Furnham, A., Rehim, S., et al. (2011). Conspiracist ideation in Britain and Austria: Evidence of a monological belief system and associations between individual psychological differences and real-world and fictitious conspiracy theories. British Journal of Psychology, 102, 443-463. doi: $10.1111 / \mathrm{j} .2044-8295.2010 .02004 . x$

Swami, V., \& Furnham, A. (2012). Examining conspiracist beliefs about the disappearance of Amelia Earhart. The Journal of General Psychology, 139, 244-259. doi: $10.1080 / 00221309.2012 .697932$

Swami, V., \& Furnham, A. (2014). Political paranoia and conspiracy theories. In J.-P. Prooijen, \& P. A. M. van Lange (Eds.), Power, politics, and paranoia: Why people are suspicious of their leaders (pp. 218-236). Cambridge: Cambridge University Press. 
Swami, V., Pietschnig, J., Tran, U. S., Nader, I. W., Stieger, S., \& Voracek, M. (2013). Lunar lies: The impact of informational bias and individual differences in shaping conspiracist beliefs about the moon landings. Applied Cognitive Psychology, 27, 71-80. doi: 10.1002/acp.2873

Swami, V., Voracek, M., Stieger, S., Tran, U. S., \& Furnham, A. (2014). Analytic thinking reduces belief in conspiracy theories. Cognition, 133, 572-585. doi: 10.1016/j.cognition.2014.08.006

van der Linden, S. (2015). The conspiracy-effect: Exposure to conspiracy theories (about global warming) decreases pro-social behavior and science acceptance. Personality and Individual Differences, 87, 171-173. doi: 10.1016/j.paid.2015.07.045

van der Tempel, J., \& Alcock, J. (2015). Relationships between conspiracy mentality, hyperactive agency detection, and schizotypy: Supernatural forces at work? Personality and Individual Differences, 82, 136-141. doi: 10.1016/j.paid.2015.03.010

van Elk, M. (2015). Perceptual biases in relation to paranormal and conspiracy beliefs. PLoS One, 10, e0130422. doi: 10.1371/journal.pone.0130422

Widiger, T. A., \& Trull, T. J. (2007). Plate tectonics in the classification of personality disorder. American Psychologist, 62, 71-83. doi: 10.1037/0003-066X.62.2.71

Wright, A. G. C., Thomas, K. M., Hopwood, C. J., Markon, K. E., Pincus, A. L., \& Krueger, R. F. (2012). The hierarchical structure of $D S M-5$ pathological personality traits. Journal of Abnormal Psychology, 121, 951-957. doi: 10.1037/a0027669 
Table 1. Internal Consistency Coefficients (Cronbach's $\alpha$ ) for the Personality Inventory for

DSM-5 Domain and Facet Scores and Correlations with Belief in Conspiracy Theories

\begin{tabular}{|c|c|c|}
\hline PID-5 Domains and Facets & Cronbach's $\alpha$ & Correlation with BCTI \\
\hline$\underline{\text { Antagonism Domain }}$ & .90 & .41 \\
\hline Manipulativeness & .85 & .37 \\
\hline Deceitfulness & .90 & .37 \\
\hline Callousness & .94 & .43 \\
\hline Grandiosity & .87 & .39 \\
\hline Attention Seeking & .93 & .38 \\
\hline$\underline{\text { Psychoticism Domain }}$ & .94 & .49 \\
\hline Perceptual Dysregulation & .94 & .46 \\
\hline Eccentricity & .96 & .45 \\
\hline Unusual Beliefs and Experiences & .91 & .48 \\
\hline$\underline{\text { Disinhibition Domain }}$ & .89 & .42 \\
\hline Rigid Perfectionism & .91 & .35 \\
\hline Impulsivity & .88 & .39 \\
\hline Irresponsibility & .88 & .40 \\
\hline Distractibility & .92 & .37 \\
\hline Risk Taking & .86 & .24 \\
\hline$\underline{\text { Negative Affectivity Domain }}$ & .87 & .40 \\
\hline Emotional Lability & .89 & .39 \\
\hline Perseveration & .92 & .41 \\
\hline Anxiousness & .90 & .26 \\
\hline Separation Insecurity & .88 & .40 \\
\hline Hostility & .91 & .35 \\
\hline Submissiveness & .85 & .29 \\
\hline Suspiciousness & .75 & .44 \\
\hline Detachment Domain & .91 & .34 \\
\hline Restricted Affectivity & .89 & .32 \\
\hline Anhedonia & .89 & .29 \\
\hline Depressivity & .96 & .39 \\
\hline Withdrawal & .93 & .27 \\
\hline
\end{tabular}


Intimacy Avoidance

.89

.34

Note. PID-5 = Personality Inventory for the DSM-5; BCTI = Belief in Conspiracy Theories

Inventory. Correlation coefficients in bold represent $r \geq|.43|$; all correlation coefficients are significant at $p<.001$. 
Table 2. Regression Coefficients for the Analysis with the Five PDI-5 Facets as Predictor Variables

\begin{tabular}{lccccc}
\hline Facet & B & SE & $\beta$ & $t$ & $p$ \\
\hline Unusual Beliefs and Experiences & .36 & .16 & .27 & 2.17 & .031 \\
Perceptual Dysregulation & -.06 & .21 & -.05 & -0.30 & .767 \\
Eccentricity & .18 & .13 & .14 & 1.42 & .157 \\
Suspiciousness & .33 & .13 & .20 & 2.60 & .010 \\
Callousness & .03 & .17 & .02 & 0.15 & .882 \\
\hline
\end{tabular}

